\title{
CHANGING INDICATIONS FOR PENETRATING KERATOPLASTY, 1971-1990
}

\author{
K. W. SHARIF and T. A. CASEY $\dagger$ \\ East Grinstead
}

\begin{abstract}
SUMMARY
We report a retrospective analysis of the clinical indications for 3555 penetrating keratoplasties performed at our department between 1971 and 1990 . The cases were distributed among 12 diagnostic categories. Regrafting was the most common indication overall, accounting for 1452 cases $(\mathbf{4 0 . 8 \%})$. Other major indications were, in order of decreasing frequency, keratoconus $(17 \%)$, scarring secondary to herpes simplex keratitis $(11.7 \%)$, aphakic bullous keratopathy (5.9\%) and interstitial keratitis $(5 \%)$. Further analysis of the relative percentages in each category within each 5-year interval of the study period was carried out to identify any changes in incidence. Viral disease as an indication for penetrating keratoplasty has shown a gradual decrease in frequency, accounting for only $6.4 \%$ of the cases during the last 5 -year period (1986-90) compared with $19.6 \%$ during the first 5 years (1971-75). This finding is consistent with the marked improvement in the recognition and medical treatment of herpes simplex keratitis. The increase in incidence of grafting for pseudophakic bullous keratopathy in 1986-90 (6.7\%) compared with 1981-85 (1.1\%) correlates well with the dramatic increase in the number of cataract extractions with intraocular lens implantations performed during that period.
\end{abstract}

The indications for penetrating keratoplasty have gradually changed over the past 20 years, reflecting changes in the incidence and management of various corneal disorders, as well as the incidence and effect of other ocular surgical procedures. ${ }^{1-6}$ Continued improvement in surgical technique, instrumentation and donor tissue preservation have made corneal grafting a highly successful surgical procedure, with a subsequent increase in the number of penetrating keratoplasties performed and a broadening of their indications. In order to assess the vari-

\footnotetext{
†This paper is dedicated to the late Tom Casey and the significant contribution he made to British and international ophthalmology.

Correspondence to: Khaled W. Sharif, FRCS, FCOphth, Department of Ophthalmology, Jordan University Hospital, PO Box 13345 , Amman, Jordan.

From: Corneoplastic Unit and National Eye Bank, Queen Victoria Hospital, East Grinstead, Sussex RH19 3DZ, UK.
}

ous changes that have occurred we reviewed the clinical indications for all the penetrating keratoplasties performed between 1971 and 1991 in the Corneoplastic Unit, Queen Victoria Hospital, East Grinstead; this is a tertiary referral centre specialising in corneal and oculoplastic surgery.

\section{MATERIALS AND METHODS}

We reviewed the clinical charts of all the patients who had undergone penetrating keratoplasty at our unit during the 20-year period from 1 January 1971 to 31 December 1990. Information obtained included date of surgery, patient age, and the pre-operative clinical diagnosis for which the operation was performed. When clinical information regarding the diagnosis was insufficient, additional details were obtained by examining the histopathological report to identify more clearly the disease present. The final diagnosis was arrived at by the correlation of the clinical and pathological features.

The cases were distributed among 12 diagnostic categories. The category of regraft included any eye that underwent penetrating keratoplasty which had had a previous transplant. This category was further analysed for the aetiology of failure of the previous graft in each case. In cases of pseudophakic bullous keratopathy, information was obtained regarding the type of intraocular lens and correlated to the year of transplantation.

Further analysis of the relative percentages in each of the 12 categories within each 5-year interval of the study period was performed to identify any changes in incidence.

\section{RESULTS}

A total of 3555 full-thickness corneal transplants were performed between 1971 and 1990. An average of 178 penetrating keratoplasties were performed each year, ranging from 78 in 1971 to 321 in 1990. Analysing the number of operations performed within each 5-year interval of the study period showed that a large number of cases were performed between 1981 and 1985 (Table I).

The average age of patients undergoing penetrating ker- 
Table I. Indications for penetrating keratoplasty, 5-year intervals (January 1971-December 1990)

\begin{tabular}{|c|c|c|c|c|c|}
\hline Indication & $1971-75$ & $1976-80$ & $1981-85$ & $1986-90$ & Total \\
\hline 1. Fuchs' dystrophy & $36(4.8 \%)$ & $14(1.5 \%)$ & $48(4.5 \%)$ & $42(4.7 \%)$ & $140(3.9 \%)$ \\
\hline 2. Pseudophakic bullous keratopathy & - & - & $12(1.1 \%)$ & $60(6.7 \%)$ & $72 \quad(2 \%)$ \\
\hline 3. Keratoconus & $141(18.8 \%)$ & $168(19.1 \%)$ & $117(11.2 \%)$ & $171(19.2 \%)$ & $597(16.8 \%)$ \\
\hline 4. Aphakic bullous keratopathy & $30 \quad(4 \%)$ & $102(11.6 \%)$ & $42 \quad(4 \%)$ & $36 \quad(4 \%)$ & $210(5.9 \%)$ \\
\hline 5. Regraft & $225(30.1 \%)$ & $312(35.6 \%)$ & $537 \quad(51 \%)$ & $378(42.5 \%)$ & $1452(40.8 \%)$ \\
\hline 6. Scarring due to herpes simplex keratitis & $147(19.6 \%)$ & $90(10.2 \%)$ & $123(11 \%)$ & $57(6.4 \%)$ & $417(11.7 \%)$ \\
\hline 7. Scarring due to interstitial keratitis & $72(9.6 \%)$ & $42(4.7 \%)$ & $36(3.4 \%)$ & $30(3.3 \%)$ & $(5 \%)$ \\
\hline 8. Trauma & $36(4.8 \%)$ & $(2 \%)$ & $39(3.7 \%)$ & $12(1.3 \%)$ & $105(2.9 \%)$ \\
\hline 9. Infection & $3(0.4 \%)$ & $3(0.3 \%)$ & - & - & $6(0.1 \%)$ \\
\hline 10. Other dystrophies & $39(5.2 \%)$ & $39(4.4 \%)$ & $51 \quad(4.8 \%)$ & $60(6.7 \%)$ & $189(5.3 \%)$ \\
\hline 11. Chemical burns & $15 \quad(2 \%)$ & $12(1.3 \%)$ & $6(0.5 \%)$ & $12(1.3 \%)$ & $45(1.2 \%)$ \\
\hline 12. Degenerations & - & $9 \quad(1 \%)$ & $3(0.2 \%)$ & $3(0.3 \%)$ & $15(0.4 \%)$ \\
\hline 13. Miscellaneous/unknown & $30 \quad(4 \%)$ & $36 \quad(4.1 \%)$ & $30(2.8 \%)$ & $(1 \%)$ & $105(2.9 \%)$ \\
\hline Total & $747(100 \%)$ & $876(100 \%)$ & $1044(100 \%)$ & $888(100 \%)$ & $3555(100 \%)$ \\
\hline
\end{tabular}

atoplasty was 59 years (range 2 months to 95 years). We could not identify any significant change in age characteristics during the study period.

Regrafting was the most common indication, accounting for 1452 cases $(40.8 \%)$ of all penetrating keratoplasties performed (Table I). Further analysis of this category to identify the indications for regrafting (i.e. causes of failure of the previous transplant) showed that the commonest cause of repeat grafting was endothelial decompensation (Table II). This accounted for 563 regrafts of which 65 cases presented with primary graft failure while the remaining 498 cases had late endothelial decompensation. Over $76 \%$ of graft failures due to endothelial decompensation occurred in grafts performed during the first 10 years of the study.

The second most common cause for repeat penetrating keratoplasty was endothelial rejection, which occurred in 640 cases $(3.6 \%)$ of the regraft category. Graft rejection was diagnosed by the appearance in a previously clear graft of at least one of the following: (1) endothelial rejection line, (2) keratic precipitates and (3) localised graft oedema, the edge of which usually coincided with the keratic precipitates.

The least common indication for repeat grafting was high post-keratoplasty astigmatism that could not be successfully corrected with contact lenses or refractive surgery; this accounted for $2 \%$ of the regrafts.

Keratoconus, scarring secondary to herpes simplex keratitis and aphakic bullous keratopathy as indications for penetrating keratoplasty all followed regrafting in frequency, accounting for 597 (16.8\%), 417 (11.7\%) and 210 (5.9\%) cases, respectively.

Table II. Indications for repeat grafting, 1971-90

\begin{tabular}{lc}
\hline Indication & No. of cases \\
\hline Late endothelial decompensation & 498 \\
Primary graft failure & 65 \\
Rejection & 460 \\
Glaucoma & 132 \\
Herpes simplex keratitis & 72 \\
Infection (bacterial/fungal) & 84 \\
Recurrence of original dystrophy in the graft & 111 \\
High astigmatism & 30 \\
Total & 1452 \\
\hline
\end{tabular}

Keratoconus showed little significant change over the study period. Herpes simplex keratitis, however, decreased in frequency, from 147 of 747 cases (19.6\%) in the first 5-year interval to 57 of 888 cases $(6.4 \%)$ in the last 5-year interval (Fig. 1). Interstitial keratitis demonstrated a similar decrease in frequency, from $9.6 \%$ of the cases in $1971-75$ to $3.3 \%$ in $1986-90$ (Figs. 2 and 3).

Pseudophakic bullous keratopathy showed a sixfold increase in incidence as an indication for grafting between 1981-85 (1.1\%) and 1986-90 (6.7\%) (Table I). Of the 72 cases of pseudophakic bullous keratopathy, 54 (75\%) were associated with anterior chamber intraocular lenses (Table III). This association demonstrated a constant increase in frequency, from 6 of 12 cases $(50 \%)$ in $1981-85$ to 48 of 60 cases (80\%) in 1986-90.

Iris-fixation lenses accounted for 10 of the total of 72 cases $(13.9 \%)$, but showed a gradual decrease in frequency from 4 of 12 cases (33.3\%) in 1981-85 to 6 of 60 cases $(10 \%)$ in $1986-90$.

Posterior chamber lenses were found in 8 of the 72 eyes $(11.1 \%)$ over the period of the study. The commonest dystrophy requiring corneal grafting in our study was Fuchs' dystrophy, whch accounted for 140 penetrating kerato-

Table III. Type of intraocular lens (IOL) in pseudophakic bullous keratopathy

\begin{tabular}{lcrrr}
\hline IOL type & $1981-85$ & \multicolumn{1}{c}{$1986-90$} & \multicolumn{2}{c}{ Total } \\
\hline Anterior chamber & $6(50 \%)$ & $48(80 \%)$ & $54(75 \%)$ \\
Iris fixated & $4(33.3 \%)$ & $6(10 \%)$ & $10(13.9 \%)$ \\
Posterior chamber & $2(16.7 \%)$ & $6(10 \%)$ & $8(11.1 \%)$ \\
Total & $12(100 \%)$ & $60(100 \%)$ & $72(100 \%)$ \\
\hline
\end{tabular}

Table IV. Penetrating keratoplasty for corneal dystrophies, 1971-90

\begin{tabular}{lc}
\hline Diagnosis & No. of cases \\
\hline Fuchs' dystrophy & 140 \\
Reis-Buckler dystrophy & 73 \\
Lattice dystrophy & 51 \\
Macular dystrophy & 24 \\
Granular dystrophy & 15 \\
Posterior polymorphous dystrophy & 9 \\
Schnyder's crystalline dystrophy & 8 \\
Congenital hereditary endothelial dystrophy & 7 \\
Anterior membrane dystrophy (Grayson-Wilbrandt) & 2 \\
Total & 329 \\
\hline
\end{tabular}




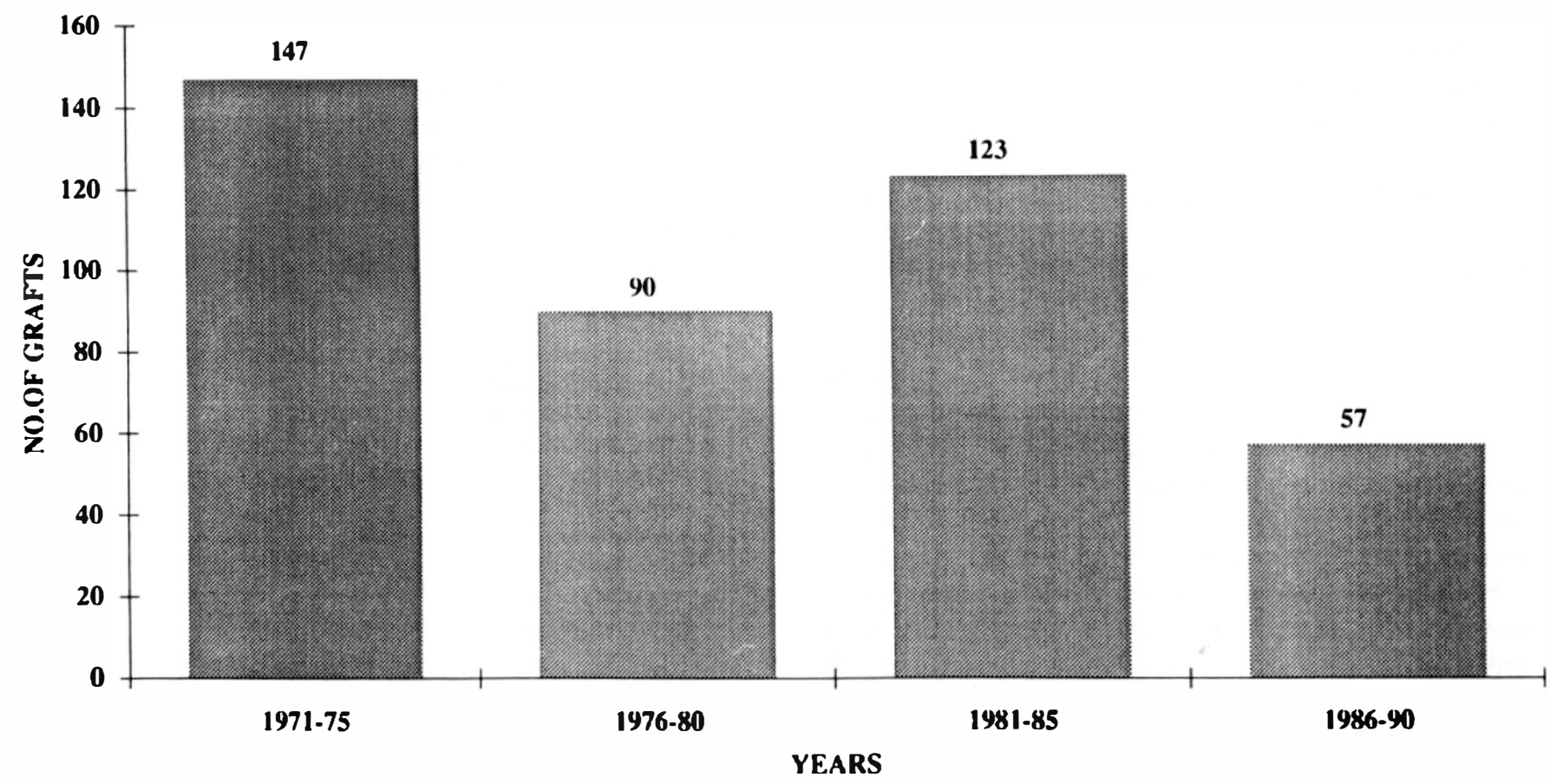

Fig. 1. Penetrating keratoplasty performed in eyes with corneal scarring caused by herpes simplex keratitis between January 1971 and December 1990 (5-year intervals) $(n=417)$.

plasties (3.9\%). The total number of grafts performed for other corneal dystrophies was 189 (5.3\%). Further analysis of this category demonstrated that after Fuchs' dystrophy the second most common dystrophy requiring grafting was Reis-Buckler dystrophy ( 73 cases), followed by lattice dystrophy ( 51 cases) and macular dystrophy ( 24 cases) (Table IV). Degenerative conditions accounted for 105 cases $(2.9 \%)$ of the total grafts in our study. This category included, in order of decreasing frequency, Salzman's nodular degeneration (49 cases), spheroidal degeneration (36 cases), calcareous degeneration (10 cases) and lipid degeneration (10 cases).

\section{DISCUSSION}

In the 20-year period from January 1971 to December 1990,3555 penetrating keratoplasties were performed in our unit. The most common indication was regrafting,

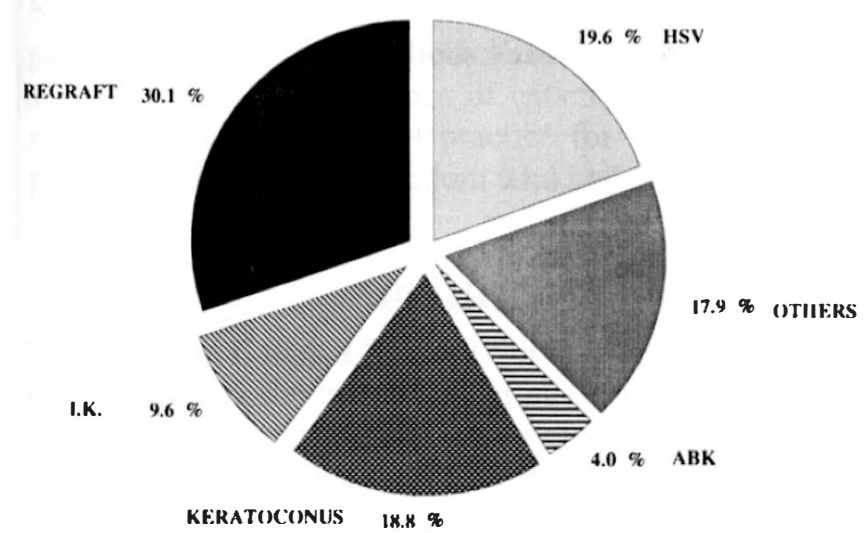

Fig. 2. Indications for corneal grafting, 1971-75 $(n=747)$. $H S V$, herpes simplex keratitis; I.K., interstitial keratitis; $A B K$, aphakic bullous keratopathy. which accounted for 1452 cases $(40.8 \%)$. This is far higher than in most published series, ${ }^{1-6}$ reflecting the tertiary referral nature of this unit as evidenced by the fact that 852 of these repeat grafts $(58.6 \%)$ had had the previous graft performed elsewhere. Late endothelial decompensation and rejection were the reasons for the failure of most of these grafts (Table II). There was a remarkable decrease in the number of graft failures due to endothelial decompensation over the last 10 years of the study period; $24 \%$ of such failures occurred in the last 10 years as opposed to $76 \%$ in the first 10 years. This finding could be attributed to the recent improvements in corneal surgical techniques and instrumentation. ${ }^{6}$ Furthermore, improvement in eye-banking techniques have dramatically improved the quality and availability of donor corneal tissue over the past 10 years.

The other major indications for keratoplasty were, in

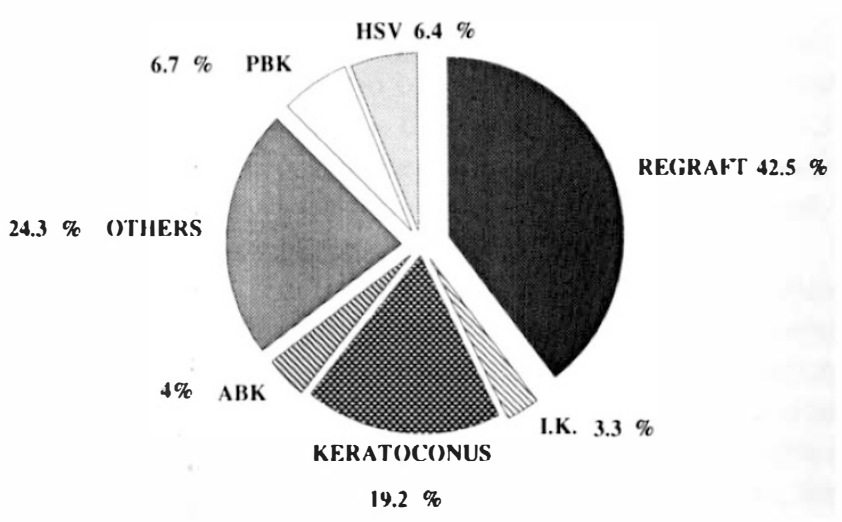

Fig. 3. Indications for corneal grafting, 1986-90 $(n=888)$. $H S V$, herpes simplex keratitis; I.K., interstitial keratitis; $A B K$, aphakic bullous keratopathy; PBK, pseudophakic bullous keratopathy. 
order of decreasing frequency, keratoconus (16.8\%), scarring due to herpes simplex keratitis $(11.7 \%)$, corneal dystrophies $(9.2 \%)$, aphakic bullous keratopathy (5.9\%) and interstitial keratitis $(5 \%)$.

There are some interesting trends in the frequencies of indications for corneal grafting over this 20 -year period, as highlighted in the differences between Figs. 2 and 3. Pseudophakic bullous keratopathy has recently been the commonest indication for corneal grafting in the United States. ${ }^{2},{ }^{6-11}$ In our study period it appeared only recently, and although it increased from $1.1 \%$ to $6.7 \%$ in the last decade (Table I), this is still a relatively low proportion. This again may reflect referral practices in United Kingdom. The variation in the number of cases of aphakic bullous keratopathy is undoubtedly due to the shift towards implantation of intraocular lenses in cataract surgery.

Fuchs' dystrophy, other dystrophies and keratoconus have remained static as indications. It might have been expected that with better contact lens technology and fitting, corneal grafting for keratoconus might be delayed until later in the degenerative process, with a subsequent decrease in the relative percentage of total grafts it accounted for. However, this trend may have been offset by earlier grafting in some cases due to improvements in expected outcome. ${ }^{12}$

The number of penetrating keratoplasties for interstitial keratitis decreased markedly in our series in the 1970s, as would be expected with efficient medical control of the causes. This supports the findings of other published series in the United States. ${ }^{3,6}$ Herpetic keratitis has declined steadily as an indication for grafting over the last 20 years (Fig. 1), consistent with the development of better antiviral agents and improved medical management of the condition in general. ${ }^{2,13}$

The total number of grafts performed annually in our unit has not changed significantly over the last two decades. There have been decreases in the numbers of grafts for certain indications but these have been offset by the appearance of new indications, such as pseudophakic bullous keratopathy, and possibly by the earlier intervention in other conditions and reintervention where grafts have failed. It may be that technological and pharmacological advances have produced better results from grafting over the last 20 years, but as the procedure is performed for a variety of indications in more complicated cases, the expectations of both patients and surgeons are increasing and demand even greater attention to detail in the practice of penetrating keratoplasty.

\section{REFERENCES}

1. Smith RE, McDonald HR, Nesburn AB, Minckler DS. Penetrating keratoplasty: changing indications, 1974 to 1978. Arch Ophthalmol 1980;98:1226-9.

2. Brady SE, Rapuans CJ, Arensten JJ, Cohen EJ, Laibson PR. Clinical indications for and procedures associated with penetrating keratoplasty, 1983-88. Am J Ophthalmol 1989;108:118-22.

3. Arensten JJ, Morgan B, Green WR. Changing indications for keratoplasty. Am J Ophthalmol 1976;81:313-8.

4. Lemp MA. Indications for penetrating keratoplasty. Med Ann DC 1972;41:346-50.

5. Chandler JW. Indications for penetrating keratoplasty and management of cases. Trans Pacific Coast Oto-ophthalmol Soc 1976;57:97-104.

6. Robin JB, Gindi JJ, Koh K, Schanzlin DJ, Rao NA, York $\mathrm{KK}$, Smith RE. An update of the indications for penetrating keratoplasty, 1979-83. Arch Ophthalmol 1986;104:87-9.

7. Schanzlin DJ, Robin JB, Gomez DS. Results of penetrating keratoplasty for aphakic and pseudophakic bullous keratoplasty. Am J Opthalmol 1984;98:302-12.

8. Stark WJ, Leske MC, Worthen DM. Trends in cataract surgery and intraocular lenses in the United States. Am J Ophthalmol 1983;96:304-10.

9. Meyer RF, Sugar A. Penetrating keratoplasty in pseudophakic bullous keratopathy. Am J Ophthalmol 1980;90:677-81.

10. Waring GO III, Welch SN, Cavanagh HD. Results of penetrating keratoplasty in 123 eyes with pseudophakic or aphakic corneal edema. Ophthalmology 1983;90:25-33.

11. Stark WJ, Maumenee AE. Update of the intraocular lens: experience at the Wilmer Institute. Ophthalmologica 1983;187:65-73.

12. Sharif KW, Casey TA. Penetrating keratoplasty for keratoconus: complications and long term success. $\mathrm{Br} \mathrm{J}$ Ophthalmol 1991;75:142-6.

13. Ficker LA, Kirkness CM, Rice NSC, Steele ADMcG. The changing management and improved prognosis for corneal grafting in herpes simplex keratitis. Ophthalmology 1989;96:1587-96. 